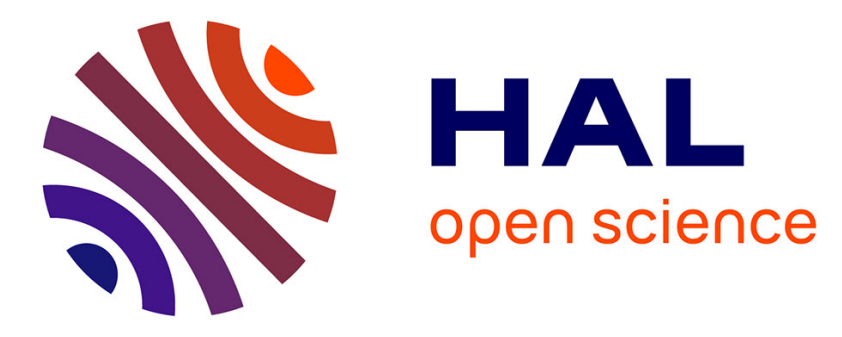

\title{
Modeling heat and mass transfer limitation processes of gas hydrate formation under slug flow
}

Carlos Lange-Bassani, Fausto A. A. Barbuto, Rigoberto E.M. Morales, Ana

Cameirão, Jean-Michel Herri, Amadeu K. Sum

\section{To cite this version:}

Carlos Lange-Bassani, Fausto A. A. Barbuto, Rigoberto E.M. Morales, Ana Cameirão, Jean-Michel Herri, et al.. Modeling heat and mass transfer limitation processes of gas hydrate formation under slug flow. 25th International Congress of Mechanical Engineering - COBEM 2019, School of Mechanical Engineering of the Federal University of Uberlandia (UFU), Oct 2019, Uberlândia, Brazil. emse02549335

\section{HAL Id: emse-02549335 \\ https://hal-emse.ccsd.cnrs.fr/emse-02549335}

Submitted on 21 Apr 2020

HAL is a multi-disciplinary open access archive for the deposit and dissemination of scientific research documents, whether they are published or not. The documents may come from teaching and research institutions in France or abroad, or from public or private research centers.
L'archive ouverte pluridisciplinaire HAL, est destinée au dépôt et à la diffusion de documents scientifiques de niveau recherche, publiés ou non, émanant des établissements d'enseignement et de recherche français ou étrangers, des laboratoires publics ou privés. 


\title{
MODELING HEAT AND MASS TRANSFER LIMITATION PROCESSES OF GAS HYDRATE FORMATION UNDER SLUG FLOW
}

Carlos L. Bassani, langebassani@gmail.com

Fausto A.A. Barbuto, fausto_barbuto@yahoo.ca

Rigoberto E.M. Morales, rmorales@utfpr.edu.br

Multiphase Flow Research Center (NUEM), Federal University of Technology - Paraná (UTFPR), Rua Deputado

Heitor Alencar Furtado, 5000, Bloco N, CEP 81280-340, Curitiba/PR, Brazil

Ana Cameirão, cameirao@emse.fr

Jean-Michel Herri, herri@emse.fr

Mines Saint-Etienne, Univ Lyon, CNRS, UMR 5307 LGF, Centre SPIN, Departement PEG, F - 42023 Saint-Etienne

France

Amadeu K.Sum, asum@mines.edu

Phases to Flow Laboratory, Chemical and Biological Engineering Department, Colorado School of Mines, 1500 Illinois

St., Golden, CO 80401, USA

\begin{abstract}
This article presents the coupling of a crystallization model of gas hydrate to a mechanistic gas-liquid slug flow model in order to understand: (i) heat transfer limitation processes due to reheating of mixture and consequent decrease of crystallization driving force; and (ii) mass transfer limitation due to porosity evolution of the crystalline structure. Application is in flow assurance of gas and oil production operations.
\end{abstract}

Keywords: flow assurance, gas hydrates, multiphase flow, crystallization

\section{INTRODUCTION}

Gas hydrates are crystals formed by the trapping of gas molecules inside cages made of hydrogen-bonded water molecules (Sum et al., 2009). Both multiphase flow and gas hydrate formation have been widely studied due to their application in oil and gas production operations, and to this date relevant advances in modeling and experimentation have been made. However, only recently studies coupling gas hydrate formation to multiphase flow have appeared in the literature (Bassani et al., 2018; Gong et al., 2010; Shi et al., 2018; Zerpa et al., 2013). The objective is to understand: (i) how gas consumption and heat release due to hydrate formation affect mass, momentum and energy balances of the flow; and (ii) how the thermodynamic state of the mixture and the flow interfaces influence the mass transfer process for the crystal growth kinetics. Furthermore, the existing flow pattern right before the gas hydrate onset affects the initial size of the particles (which are considered to encompass the water droplets; Melchuna et al., 2016), with consequences on the slurry stability. Pipe blockage is imminent whenever the slurry becomes unstable and settles down (Roco and Shook, 1985), what might cause flow stoppage or impairment as well as equipment malfunction, with consequential revenue losses. This is called pipeline plugging, regarded as severe and critical problem when it comes to assuring continuous flow of gas and oil production operations (Cardoso et al., 2015).

This study couples a new growth model of gas hydrates considering the interactions between the porous structure to the gas mass transfer process in the flow, inserting it into a mechanistic slug flow model (Bassani et al., 2018).

\section{MATHEMATICAL MODEL}

The liquid is regarded as a water-in-oil emulsion and the gas-liquid assumes the slug flow pattern, as depicted in Figure 1(a). Crystal nucleation occurs mainly at the surface of the droplets (Melchuna et al., 2016), quickly trapping all the available water inside the porous structure of the hydrates (hydrophilic nature; Hirata and Mori, 1998). Figure 1(b) shows the path of the gas molecules up to reaching the water inside the capillaries. Gas solubilizes in the oil, distributes throughout its bulk, transfers to the outer surface of the particles and solubilizes in the water at the capillary entrance. At this point, simultaneous gas diffusion through the capillary and crystallization on their walls occur, Figure 1(c). The modeling of these competitive phenomena yields the gas consumption rate per capillary $-d n_{g, i} /\left.d t\right|_{1 \text { cap }}$, according to Eq. (1); and the evolution in time of the gas concentration in the bulk $C_{b}$, as per Eq. (2):

$$
\begin{aligned}
& -\left.\frac{d n_{g, i}}{d t}\right|_{1 \text { cap }}=\frac{\pi r_{c}^{3 / 2}}{(1+\omega)} \sqrt{2 H_{w} D_{w} k_{i}}\left(\frac{C_{b}}{H_{o}}-f_{e q}\right) \text { with } \omega=\frac{n_{c}}{h_{m, p l b}} \frac{H_{w}}{H_{o}} \frac{r_{c}^{3 / 2}}{4 r_{p}^{2}} \sqrt{\frac{2 D_{w} k_{i}}{H_{w}}} \\
& \frac{d C_{b}}{d t}=\underbrace{\frac{k_{g / o} A_{g / o}}{\forall_{o}}\left(C_{g / o}-C_{b}\right)}_{\begin{array}{c}
\text { gas absorption from the gaseous } \\
\text { free phase by the bulk }
\end{array}}-\underbrace{\left.\frac{n_{p} n_{c}}{\forall_{o}} \frac{d n_{g, i}}{d t}\right|_{1 \text {. }}}_{\begin{array}{c}
\text { bulk depletion due } \\
\text { to hydrate formation }
\end{array}}
\end{aligned}
$$


where $r_{c}$ is the average capillary radius; $H_{w}$ and $H_{o}$ are the Henry's constant of gas in water and oil, respectively, given in their solubility form $\left[\mathrm{mol} /\left(\mathrm{m}^{3} \mathrm{~Pa}\right)\right]$ (Sander, 2015); $D_{w}$ is the gas diffusivity in water; $k_{i}$ is the constant of proportionality of the crystal integration process using a $1^{\text {st }}$ order crystallization law in terms of the fugacity difference at the growing surface (related to the local concentration coming from the mass transfer process) and the three-phase gas-water-hydrate equilibrium condition $\left(f_{e q}\right), d n_{g} /\left.d t\right|_{c r s s t}=k_{i} A_{i}\left(f-f_{e q}\right) ; k_{g / o}$ is the absorption coefficient of gas into oil; $A_{g / o}$ is the gas-oil interfacial surface; $\forall_{o}$ is the oil (bulk) volume; $C_{g / o}$ is the gas concentration at the gas-oil interface, considered as saturated (equilibrium at the interfaces), $C_{g / o}=H_{o} f_{g}$, where $f_{g}$ is the gas fugacity at the gaseous free phase; $n_{p}$ is the number of particles in the system (herein considered constant, that is, agglomeration is neglected); and $n_{c}$ is the number of capillaries per particle (which evolves in time as the capillaries fill up). Parameter $\omega$ represents the competition of mass transfer between the particle and the bulk against diffusion and crystallization resistances inside the capillary, where $h_{m, p l b}$ is the mass transfer coefficient between the particle and the bulk; and $r_{p}$ is the particle radius (considered equal to the droplet prior to the onset of hydrate formation).

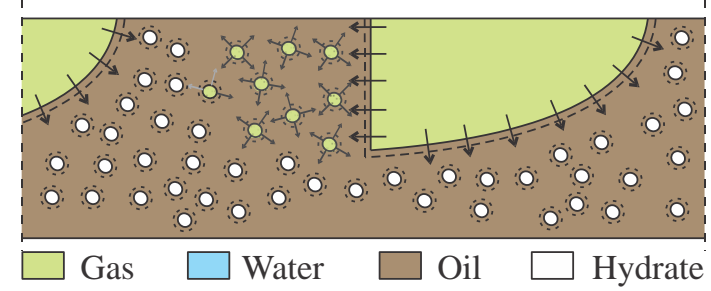

(a)

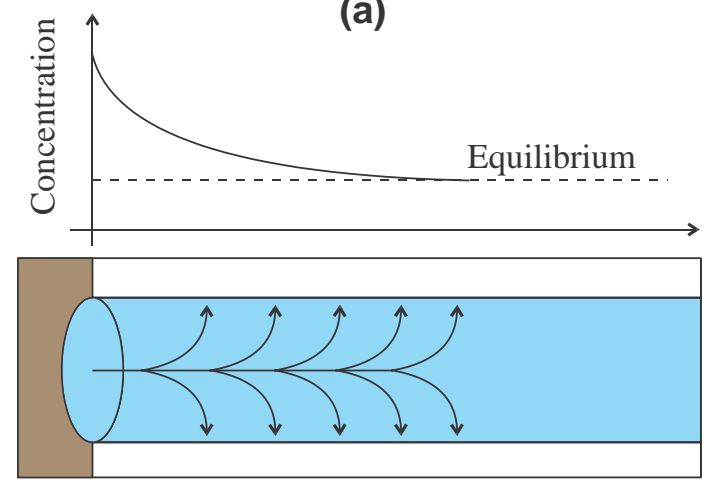

(c)

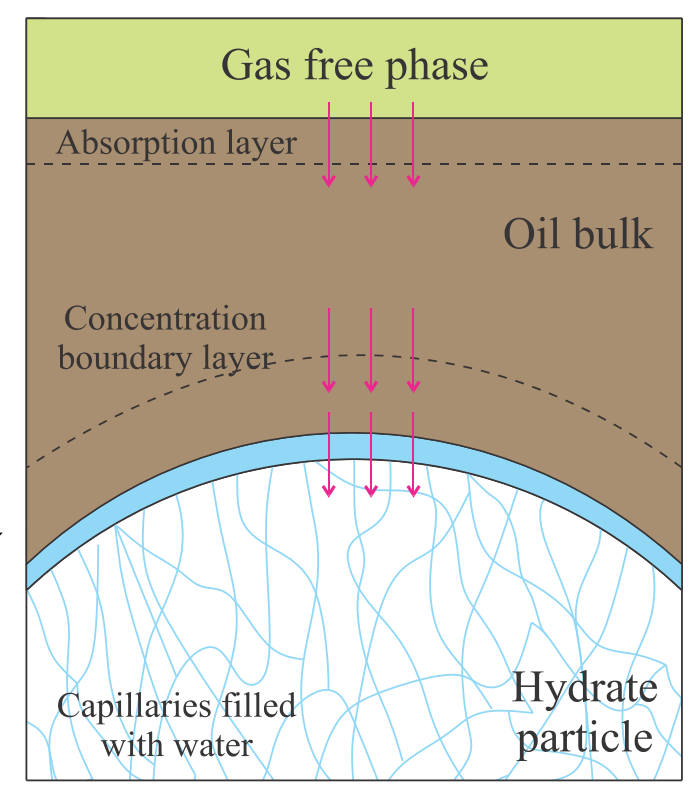

(b)

Figure 1. Multiscale problem characterization. (a) Gas-(water-in-oil) slug flow. (b) Mass transfer resistances associated to crystallization. (c) Simultaneous diffusion of gas through the capillaries and crystallization on their walls.

As crystallization takes place on the capillary walls, the capillaries fill up, squeezing some water. This squeezing might as well crack the porous structure thus forming new capillaries. Therefore, the number of open capillaries (or related surface porosity of the particle $\varepsilon_{s}=n_{c} r_{c}^{2} /\left(4 r_{p}^{2}\right)$ ) evolves in time, Eq. (3); leading to an expression for the total gas consumption rate (molar basis) due to hydrate formation $d n_{g} /\left.d t\right|_{h y d}$, Eq. (4):

$$
\begin{aligned}
& \varepsilon_{s}=\varepsilon_{s, \mathrm{in}} \exp \left[-\frac{(1-\lambda)}{(\eta+1)} \frac{r_{c, i n}}{\left(C_{0}-H_{w} f_{e q}\right)} \frac{\rho_{h}}{M_{h}} \frac{H_{w}}{k_{i}} t\right] \\
& \left.\frac{d n_{g}}{d t}\right|_{h y d}=\left.\alpha_{p} n_{p} n_{c} \frac{d n_{g, i}}{d t}\right|_{1 \text { cap }}
\end{aligned}
$$

where $\lambda$ is the birth-to-death ratio of capillaries, $\eta$ is the hydration number, $C_{0}$ is the gas concentration at the entrance of the capillaries (coming from the mass transfer system), and $\alpha_{p}$ is the number of particles submitted to crystallization, also called overall efficiency of the crystallization model. This $\alpha_{p}$-parameter appears due to the assumption of a dilute flow, where mass transfer between particle and bulk occurs through the entire spherical surface of the particle and where the bulk exists (that is, a space in the continuous phase where concentration is homogeneous). Yet not all particles interact with this 'considered bulk' in dense flows (that is, bulk does not exist in dense flows), giving rise to $0<\alpha_{p} \leq 1$, where $\alpha_{p}=1$ meaning that all the particles are crystallizing equally (dilute flow) and $\alpha_{p} \rightarrow 0$ indicating that almost no particle is crystallizing (dense flow; only particles close to gas-oil interface are crystallizing). Future modeling of gas distribution inside the oil continuous phase (that is, gas mixing inside the continuous phase) 
could be done to avoid the use of $\alpha_{p}$; herein, however, this term comes from experiments, as explained later in this article.

The number of particles and their radii are considered constant over the process. Although $100 \%$ conversion of water does not influence the particle size noticeably (which grows at a ratio of $\rho_{w} / \rho_{h} \approx 1.09$ for methane hydrates), agglomeration can drastically change the number and average size of particles. Agglomeration is neglected for the sake of simplification (cold flow assumption; Straume et al., 2019), but coupling with proper population balance models (Balakin et al., 2010; Herri et al., 1999; Sampaio et al., 2017) will be done in a near future.

The driving force for crystallization depends: (i) on the heat transfer from the multiphase flow to the outer medium (coming from the mixture energy balance); and (ii) on the pressure of the system (originating from the mixture momentum balance). By its turn, gas hydrate formation implies in: (iii) gas consumption along the pipeline, thus decelerating the mixture; (iv) heat release due to the exothermic nature of this crystallization process; and (v) mixture viscosification due to the formation of a slurry. Mathematical description of phenomena (i) to (v) is given in Bassani et al. (2018) and was a topic in prior ABCM events (Bassani et al., 2017, 2016).

\section{EXPERIMENTS AND MODEL VALIDATION}

Validation of the slug flow model against experimental data in lab conditions (small diameter, water-air flow) had already been published in Bassani et al. (2018), where pressure and temperature gradients behave with a maximum deviation of $20 \%$. For the kinetic model, the Archimède flowloop available at Mines Saint-Etienne/France was used. Schematics of this flowloop is presented in Figure 2. It is composed of a 10.2-mm ID, 30-m length downward $\left(-4^{\circ}\right)$ rolled section, a 10-m long riser and an 8-m long downward section. More detailed description of the flowloop is given by Melchuna et al. (2016). Table 1 presents the case-test used to validate the model. Fluids are deionized water and Kerdane (light oil with composition from C11 to C14; Total, 2015). Methane is solubilized into the liquid phase (i.e., there is no free gas in the circuit). The fluids are recirculated through a Moineau pump (Progressive Cavity Pump).

Basic instrumentation (temperature, pressure, pressure drop) is marked in Figure 2. The circuit is maintained at a constant pressure due to a gas injection system (called compensation system): as the gas is depleted to form hydrates causing pressure to decrease in the circuit, a PID controller opens the gas valve, allowing gas into the circuit (by the upper part of the flowloop). The gas flowrate entering the system is measured and its integrated signal gives the amount of gas consumed due to hydrate formation (which is the value used to validate the model; Figure 3). Complementary instrumentation to estimate particle size is given by Particle Video Measurement (PVM; an online microscope that takes grayscale photos of the flow in the size of $800 \times 1000 \mu \mathrm{m}$; Melchuna, 2016; Pham, 2018) and Focus Beam Reflectance Measurement (FBRM; laser that counts the chord length of the particles in the range of 1 to $1000 \mu \mathrm{m}$; Le Ba, 2009). A novelty in this study is the introduction of a sapphire window that allows High Speed Imaging (lenses with focal distance of $60 \mathrm{~mm}$, which allows visualization of structure of $0.2 \mathrm{~mm}$ or more; window size is $12 \times 52 \mathrm{~mm}$ ). The size range of droplets and particles in the case-test is in 0.4 to $2 \mathrm{~mm}$, therefore the High Speed Imaging technique was used to retrieve the flowing structure sizes, manually retrieved by using a Web Plot Digitizer (Rohatgi, 2010).

Figure 3 presents the comparison (model vs experiment) for the molar amount of gas consumed in time. The model is capable of predicting the asymptote of gas consumption due to the evolution of the porosity in time, commonly called mass transfer limitation process. Curve fitting is needed for the birth-to-death ratio of capillaries $(1-\lambda=0.019)$ and the overall efficiency of the kinetic model $\left(\alpha_{p}=0.03\right)$. Further than implying any non-considered dense flow hypothesis (as discussed in the last section), $\alpha_{p}$ also 'corrects' inconsistencies in the order of magnitude of the closure parameters chosen from literature, since exact values of some micro-scale parameters are not available. As an example, the constant of proportionality of the crystal integration process presents a range of six (6) orders of magnitude in the literature for methane hydrates $\left(k_{i} \approx 5.5 \times 10^{-12}\right.$ to $\left.1.8 \times 10^{-7} \mathrm{~mol} /\left(\mathrm{m}^{2} \cdot \mathrm{s} \cdot \mathrm{Pa}\right)\right)$; Al-Otaibi, 2009; Englezos et al., 1987; Sharma, 1996). Herein, we adopted $k_{i}=4.1 \times 10^{-11} \mathrm{~mol} /\left(\mathrm{m}^{2} \mathrm{sPa}\right)$ by considering that particles and droplets have the same size $\left(r_{p}=r_{\text {droplet }}=1 \mathrm{~mm}\right)$, that methane is saturated in both methane and water during nucleation and by retrieving $k_{i}$ from the model (model converges to expression $k_{i}=\left(4 \pi n_{d} r_{\text {droplet }}^{2}\right)^{-1}\left(f_{g}-f_{e q}\right)^{-1}\left(-d n_{g} /\left.d t\right|_{h y d, t=t_{\text {muc }}}\right)$ ). The fugacities are calculated by RefProp (Lemmon et al., 2013), which considers real behavior of methane (Setzmann and Wagner, 1991). The gaswater-hydrate equilibrium pressure for the given system temperature (required to calculate $f_{e q}$ ) comes from CSMGem (Ballard and Sloan, 2004a, 2004b). Parameters such as the initial surface porosity $\left(\varepsilon_{s, i n}=60 \%\right)$ and the capillary radius $\left(r_{c}=500 \mathrm{~nm}\right)$ were found only for permafrost hydrates (Klapp et al., 2010). 


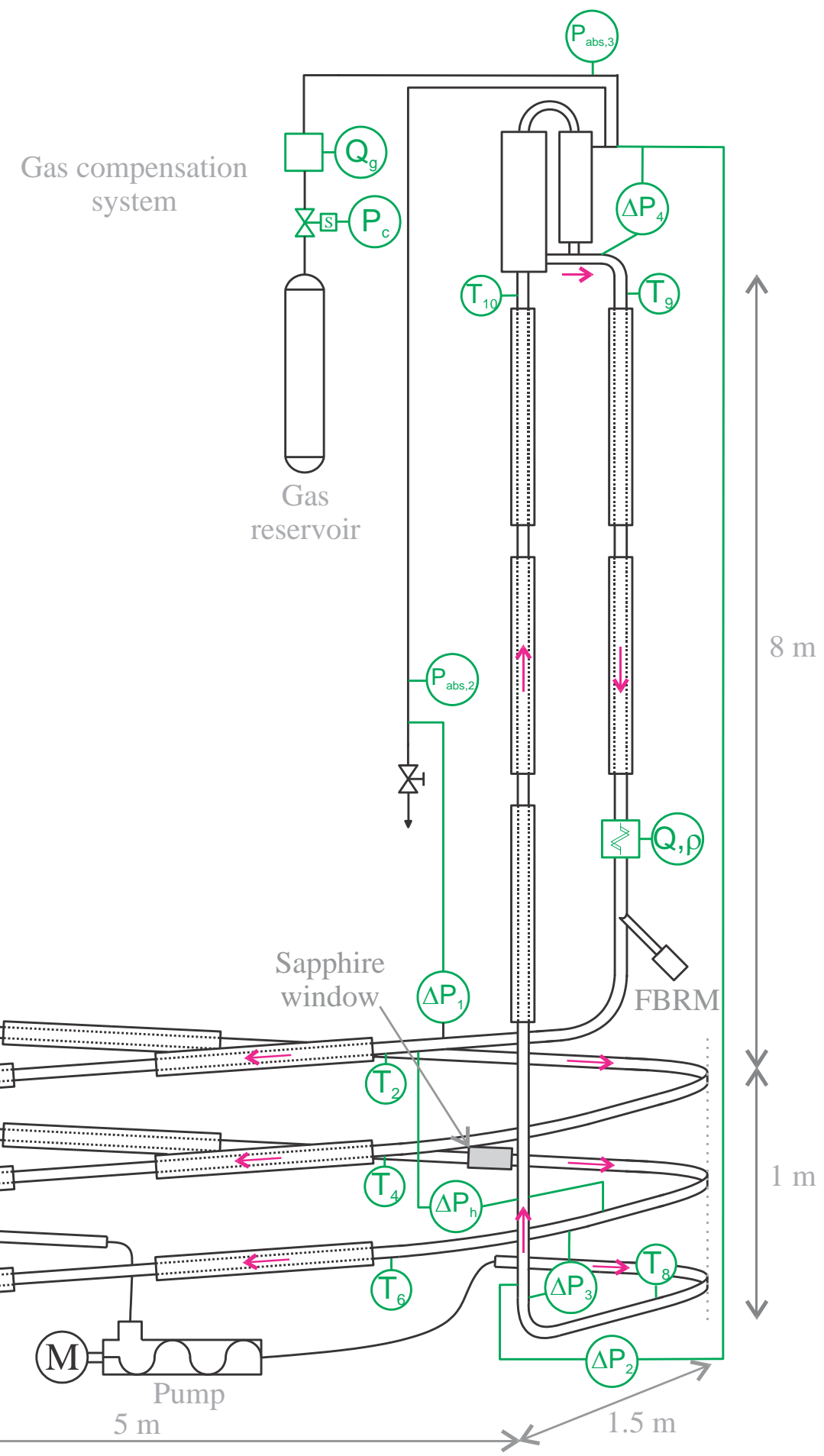

Figure 2. Schematics of Archimède flowloop at Mines Saint-Etienne/France.

Table 1. Characteristics of the experiments for methane hydrate formation in the Archimède flowloop.

\begin{tabular}{ll}
\hline Fluids & Methane / Kerdane (Total, 2015) / Deionized water \\
Pipeline internal diameter & $10.2 \mathrm{~mm}$ \\
Mixture temperature & $278 \mathrm{~K}$ \\
Mixture pressure & $80 \mathrm{bar}$ \\
Mixture velocity & $0.68 \mathrm{~m} / \mathrm{s}$ \\
Water cut & $32.25 \%$ \\
Volume of mixture inside flowloop & $10 \mathrm{~L}$ \\
Droplet radius prior to hydrates onset & $0.4-2 \mathrm{~mm}$, average radius of 1 mm \\
\hline
\end{tabular}




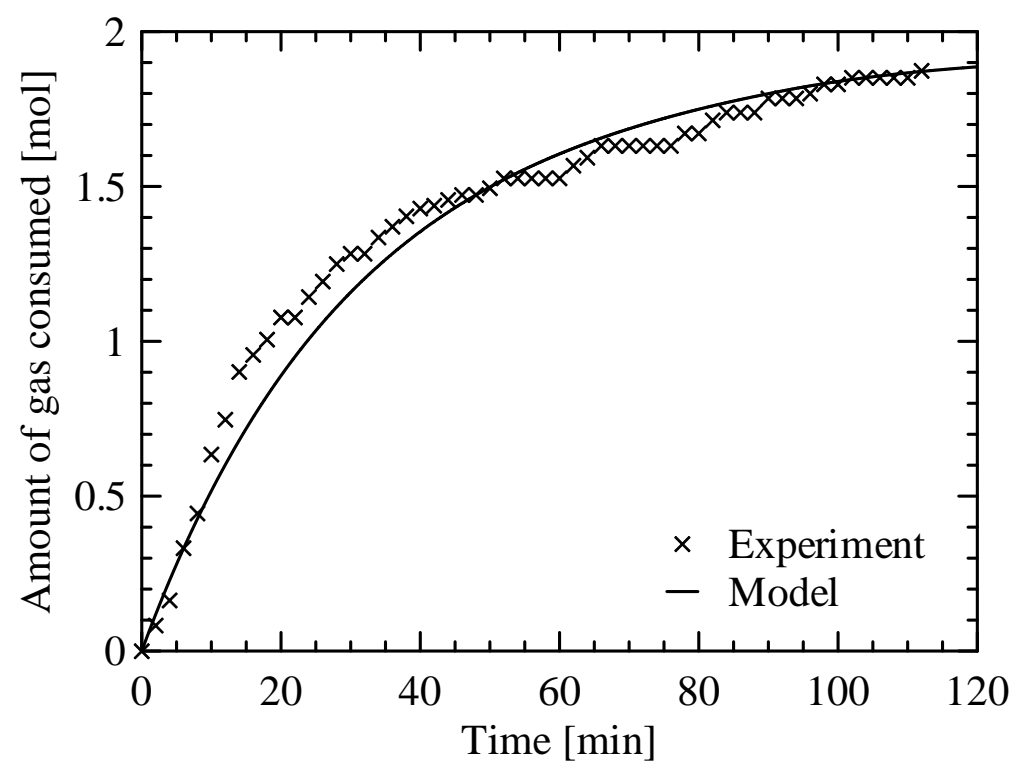

Figure 3. Validation of gas consumption over time due to hydrate formation.

\section{RESULTS AND DISCUSSIONS}

The model of gas hydrate growth kinetics coupled with multiphase flow is used to simulate a fictitious oil and gas production pipeline. Table 1 presents the input parameters used. The multiphase flow closure correlations are restricted to small pipeline diameters (here, a 75-mm ID pipeline was considered). The pipeline thickness and thermal conductivity alike are fictitious (since much smaller thermal conductivities and much larger thicknesses are used in the industry), but together they represent a conductivity heat transfer resistance that will compete with the mass transfer resistances to limit the gas hydrate formation. If a high heat transfer resistance is used, then the mixture takes a much longer time to cool down and form hydrates; during which the mixture flow reaches way farther distances; thus longer pipelines are needed. Since the closure relationships of multiphase flow were developed for small pipeline diameters, the simulation of long pipelines would cause a substantial pressure drop, and the mixture at some point leaves the formation envelope of gas hydrate. Therefore, there is still a lack of closure correlations suitable to simulating bigger pipeline diameters (and, consequently, longer pipelines). In any case, a 10-km long pipeline is simulated. The simulation time ranges from 10 to 15 minutes in an ordinary Pentium i7 desktop ( $0.5 \mathrm{~m}$ of nodal spacing).

All parameters of the kinetic model are maintained constant relatively to the last section. The sole changing parameter is the overall efficiency of the crystallization model $\alpha_{p}$. Higher values of $\alpha_{p}$ are expected in real conditions where gas flows as a free phase (remember that $\alpha_{p}=0.03$ comes from a large flowloop where gas is dissolved inside the liquid, thus only particles close to the gas-oil interface are actually crystallizing; $\alpha_{p}$ represents the amount of particles that crystallize simultaneously). Figure 4 presents the results of temperature (a) and water conversion into hydrates (b) along the pipeline for different adopted $\alpha_{p}$ 's. The model is capable of capturing two distinct trends:

(A) Heat transfer limitation (magenta line): $\alpha_{p} \rightarrow 1$ incurs in low mass transfer resistances (enhanced crystallization surface due to the existence of a good particle-bulk interaction), thus heat transfer limitation prevails. Heat transfer limitation is characterized by a reheat of the mixture towards the equilibrium temperature (Figure 4(a)), decreasing the driving force for crystallization. In this case, the porous filling-up rate is smaller, letting gas to penetrate deeper still into the capillaries and the porous structure to remain open for longer time. Therefore, higher water conversions are achieved (Figure 4(b)). Water conversion in heat transfer limited cases is characterized by a linear trend.

(B) Mass transfer limitation (red line): when $\alpha_{p} \rightarrow 0$, the problem becomes mass transfer-limited due to the small availability of active surface for crystallization. In this case, the hydrate formation rate is smaller, with consequent smaller heat release rates. Thus, the heat transfer through the wall is capable of dissipating all the heat formed during crystallization, and therefore the temperature keeps decreasing (Figure 4(a)). High driving forces are therefore maintained throughout the crystallization process and the porous structure closes relatively fast. This causes an asymptotic behavior of the water conversion along the pipeline (Figure 4(b)), characteristic of mass transfer-limited cases.

For cases with $0<\alpha_{p}<1$ (blue and green lines), there is a competition between mass and heat transfer limitations. Heat transfer initially limits hydrate formation, seen as a straight line for the water conversion (Figure 4(b)); which later 
changes to mass transfer-limited as the porous structure closes, decreasing the active surface available for crystallization, characterized by an asymptotic trend of the water conversion. All trends from Figure 4 (heat, mass, and heat + mass transfer limitations) are observed in literature of gas hydrate formation (Englezos et al., 1987; Joshi, 2012; Melchuna, 2016), although the order of magnitude of $\alpha_{p}$ should be measured in different conditions prior to industrial application of the model.

The purely limited heat transfer case causes hydrates to stop forming only when a $100 \%$ water conversion is achieved. This is however hardly ever seen in the literature, where asymptotes are usually reached after 2 to $20 \%$ (Joshi, 2012; Melchuna, 2016; Pham, 2018). This emphasizes the necessity of using a coupled mass and heat transfer-limited growth kinetic model.

Table 1. Input parameters for model evaluation.

\begin{tabular}{ll}
\hline Pipeline length / ID / thickness & $10 \mathrm{~km} / 75 \mathrm{~mm} / 2.5 \mathrm{~mm}$ \\
Pipeline inclination & Horizontal \\
Pipeline conductivity & $1 \mathrm{~W} /(\mathrm{m} . \mathrm{K})$ \\
Gas superficial velocity & $1 \mathrm{~m} / \mathrm{s}$ \\
Liquid superficial velocity & $1 \mathrm{~m} / \mathrm{s}$ \\
Water cut & $30 \%$ \\
Fluids & $\mathrm{CH}_{4} / \mathrm{H}_{2} \mathrm{O} / \mathrm{Kerdane}$ \\
Pressure at the inlet & $100 \mathrm{bar}$ \\
Temperature at the inlet & $288 \mathrm{~K}$ \\
External medium temperature & $277 \mathrm{~K}$ \\
External medium heat transfer coefficient & $100 \mathrm{~W} /\left(\mathrm{m}^{2} \mathrm{~K}\right)$ \\
\hline
\end{tabular}

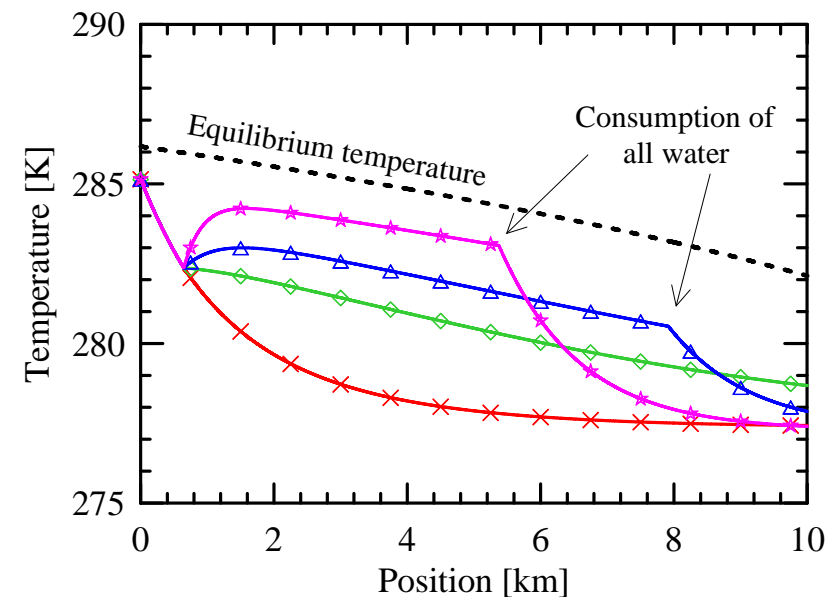

(a)

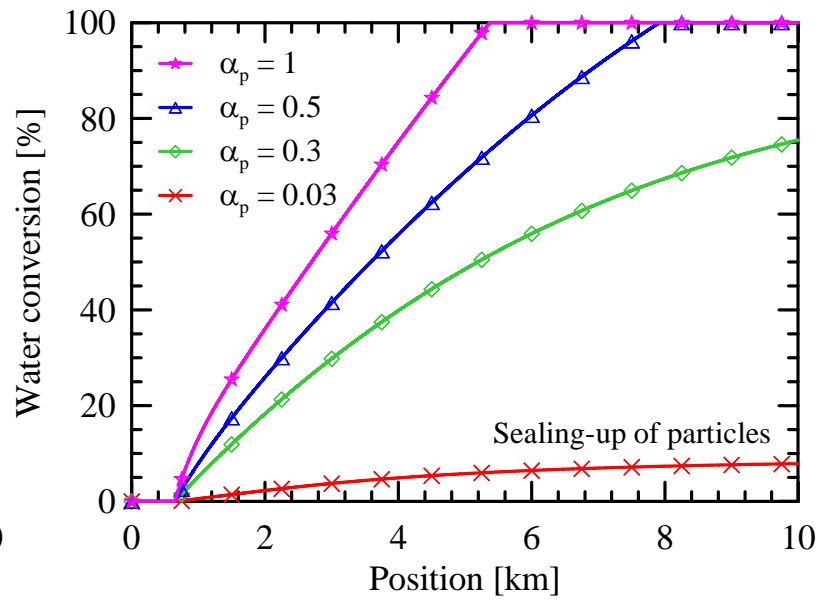

(b)

Figure 4. Sensitivity results of temperature (a) and water conversion (b) along the pipeline to the overall efficiency of the crystallization model $\alpha_{p}$. Input parameters come from Table 1.

\section{CONCLUSIONS}

A new kinetic model for gas hydrate formation in water-in-oil dispersion flows was coupled to a slug flow mechanistic model and is capable of predicting the competitive heat and mass transfer limitations in the growth process. Heat transfer limitation is characterized by mixture reheating after the onset of crystallization, with a linear trend of the water conversion along the pipeline. Mass transfer limitation, by its turn, does not reheat the mixture and presents an asymptotic trend of the water conversion. With heat transfer limitation, the hydrate structure remains 'porous' for a longer time due to the lower driving forces present at the growing surface (the capillary walls). Therefore, higher water conversions are achieved in the heat transfer-limited case.

\section{ACKNOWLEDGEMENTS}

The authors acknowledge the financial support of Région AURA Auvergne Rhône-Alpes through the project COOPERA FluEnergy, the Institut Mines-Télécom, the Coordination for the Improvement of Higher Education Personnel - Brazil (CAPES) - Finance Code 001, and TE/CENPES/PETROBRAS (5850.0103370.17.9). The authors acknowledge the technical support of M.Sc. Rafael Fabrício Alves and M.Sc. Vinícius Rodrigues de Almeida with High Speed Imaging. 


\section{REFERENCES}

Al-Otaibi, F.D., 2009. Kinetic studies of gas hydrate formation using in situ particles size analysis and Raman spectroscopy. PhD Thesis, University of Calgary, Calgary, Canada.

Balakin, B. V., Hoffmann, A.C., Kosinski, P., 2010. Population balance model for nucleation, growth, aggregation, and breakage of hydrate particles in turbulent flow. AIChE J. 56, 2052-2062. https://doi.org/10.1002/aic.12122

Ballard, A.L., Sloan, E.D., 2004a. The next generation of hydrate prediction: Part III. Gibbs energy minimization formalism. Fluid Phase Equilib. 218, 15-31. https://doi.org/10.1016/j.fluid.2003.08.005

Ballard, A.L., Sloan, E.D., 2004b. The next generation of hydrate prediction IV: A comparison of available hydrate prediction programs. Fluid Phase Equilib. 216, 257-270. https://doi.org/10.1016/j.fluid.2003.11.004

Bassani, C.L., Barbuto, F.A.A., Sum, A.K., Morales, R.E.M., 2018. A three-phase solid-liquid-gas slug flow mechanistic model coupling hydrate dispersion formation with heat and mass transfer. Chem. Eng. Sci. 178, 222237. https://doi.org/10.1016/j.ces.2017.12.034

Bassani, C.L., Barbuto, F.A.A., Sum, A.K., Morales, R.E.M., 2017. Hydrate formation effects on slug flow hydrodynamics and heat transfer: wall deposition vs. dispersion formation. In proceedings of the IV Journeys in Multiphase Flows, ABCM, JEM-2017-0015, São Paulo, Brazil.

Bassani, C.L., Barbuto, F.A.A., Sum, A.K., Morales, R.E.M., 2016. The effects of heat transfer and hydrate dispersion formations on the slug flow hydrodynamics. In proceedings of the 16th Brazilian Congress of Thermal Sciences and Engineering, ABCM, Vitória, Brazil.

Cardoso, C.A.B.R., Gonçalves, M.A.L., Camargo, R.M.T., 2015. Design options for avoiding hydrates in deep offshore production. J. Chem. Eng. Data 60, 330-335. https://doi.org/dx.doi.org/10.1021/je500601f

Englezos, P., Kalogerakis, N., Dholabhai, P.D.D., Bishnoi, P.R.R., 1987. Kinetics of formation of methane and ethane gas hydrates. Chem. Eng. Sci. 42, 2647-2658. https://doi.org/10.1016/0009-2509(87)87015-X

Gong, J., Shi, B., Zhao, J., 2010. Natural gas hydrate shell model in gas-slurry pipeline flow. J. Nat. Gas Chem. 19, 261-266. https://doi.org/10.1016/S1003-9953(09)60062-1

Herri, J.M., Pic, J.S., Gruy, F., Cournil, M., 1999. Methane hydrate crystallization mechanism from in-situ particle sizing. AIChE J. 45, 590-602.

Hirata, A., Mori, Y.H., 1998. How liquids wet clathrate hydrates: some macroscopic observations. Chem. Eng. Sci. 53, 2641-2643. https://doi.org/10.1016/S0009-2509(98)00078-5

Joshi, S. V, 2012. Experimental investigation and modeling of gas hydrate formation in high water cut producing oil pipelines. PhD Thesis, Colorado School of Mines, Golden, USA.

Klapp, S.A., Hemes, S., Klein, H., Bohrmann, G., MacDonald, I., Kuhs, W.F., 2010. Grain size measurements of natural gas hydrates. Mar. Geol. 274, 85-94. https://doi.org/10.1016/J.MARGEO.2010.03.007

Le Ba, H., 2009. Formation et agglomération de particuels d'hydrate de gaz dans une émulsion eau dans huile: étude expérimentale et modélisation. PhD Thesis, Mines Saint-Etienne, Saint-Etienne, France.

Lemmon, E.W., Huber, M.L., McLinden, M.O., 2013. Software: REFPROP Reference Fluid Thermodynamic and Transport Properties.

Melchuna, A., Cameirao, A., Herri, J.M., Glenat, P., 2016. Topological modeling of methane hydrate crystallization from low to high water cut emulsion systems. Fluid Phase Equilib. 413, $158-169$. https://doi.org/10.1016/j.fluid.2015.11.023

Melchuna, A.M., 2016. Experimental study and modeling of methane hydrates crystallization under flow from emulsions with variable fraction of water and anti-agglomerant. PhD Thesis, Mines Saint-Etienne, Saint-Etienne, France.

Pham, T.-K., 2018. Experimental Flowloop Study on Methane Hydrate Formation and Transport from Water-Oil Dispersion in Presence of Anti-Agglomerants. PhD Thesis, Mines Saint-Etienne, Saint-Etienne, France.

Roco, M.C., Shook, C.A., 1985. Critical deposit velocity in slurry flow. AIChE J. 31, 1401-1404. https://doi.org/10.1002/aic.690310821

Rohatgi, A., 2010. Software: Web Plot Digitizer 3.9.

Sampaio, T.P., Tavares, F.W., Lage, P.L.C., 2017. Non-isothermal population balance model of the formation and dissociation of gas hydrates. Chem. Eng. Sci. 163, 234-254. https://doi.org/10.1016/j.ces.2016.12.012

Sander, R., 2015. Compilation of Henry's law constants (version 4.0) for water as solvent. Atmos. Chem. Phys. 15, 4399-4981. https://doi.org/10.5194/acp-15-4399-2015

Setzmann, U., Wagner, W., 1991. A New Equation of State and Tables of Thermodynamic Properties for Methane Covering the Range from the Melting Line to $625 \mathrm{~K}$ at Pressures up to $1000 \mathrm{MPa}$. J. Phys. Chem. Ref. Data 20, 1061-1155. https://doi.org/10.1063/1.555898

Sharma, S., 1996. Gas hydrate particle size measurements. MSc Thesis, University of Calgary, Calgary, Canada

Shi, B., Liu, Y., Ding, L., Lv, X., Gong, J., 2018. New Simulator for Gas-Hydrate Slurry Stratified Flow Based on the Hydrate Kinetic Growth Model. J. Energy Resour. Technol. 141, 012906. https://doi.org/10.1115/1.4040932

Straume, E.O., Morales, R.E.M., Sum, A.K., 2019. Perspectives on Gas Hydrates Cold Flow Technology. Energy \& Fuels 33, 1-15. https://doi.org/10.1021/acs.energyfuels.8b02816 
Sum, A.K., Koh, C.A., Sloan, E.D., 2009. Clathrate Hydrates: From Laboratory Science to Engineering Practice. Ind. Eng. Chem. Res. 48, 7457-7465. https://doi.org/10.1021/ie900679m

Total, 2015. Kerdane D 75: Safety Data Sheet.

Zerpa, L.E., Rao, I., Aman, Z.M., Danielson, T.J., Koh, C.A., Sloan, E.D., Sum, A.K., 2013. Multiphase flow modeling of gas hydrates with a simple hydrodynamic slug flow model. Chem. Eng. Sci. 99, $298-304$. https://doi.org/10.1016/j.ces.2013.06.016 